\title{
Analisis Karakteristik Parkir, Drop Off dan Pick Up Area berdasarkan Demand Bandara Juanda Surabaya
}

\author{
Nafilah El Hafizah ${ }^{1 *}$ dan Mutiara Firdausi ${ }^{1}$ \\ ${ }^{1}$ Program Studi Teknik Sipil, Fakultas Teknik Sipil dan Perencanaan, Institut Teknologi Adhi Tama Surabaya \\ Email: "
}

\begin{abstract}
Juanda Airport as one of airports in Indonesia has served domestic and international flight. Airports are usually located in outlying areas accessible via direct access freeways or transit lines rather than at the center of metropolitan areas restricted by local grid networks, so their market area can be measured. The modes used at Juanda airport are dominated by private vehicles and cab. And it caused a lot of queue in the drop zone area at the peak hour and also needed some additional parking area which has overloaded in capacity. This needs sould important in order to maximize the need for facilities related to the use of access modes to the airport. The method used is to identify the use of vehicles that access the airport, evaluate the performance of parking lots, evaluate of pick up and drop off area, evaluate the number of queues at the drop off and pick up area and when if mass transportation is held to provide access modes to the airport. The result shows that private vehicles dominate as vehicles accessing the airport by $87,78 \%$ and public vehicles by 12,23\%. Peak hours of vehicles arrival at 9 AM. The analysis of the use of the drop off area a queue of vehicles by $87,57 \%$ and demand in the parking lots of 60,37\%. From the proposal of using mass transportation to reduce queue in the drop zone area by $12,42 \%$ and reduction in parking lots demand by $39,62 \%$.
\end{abstract}

Keywords: airport, parking lots, drop off area, mass transportation.

\begin{abstract}
Abstrak
Bandara Juanda merupakan salah satu bandara yang melayani penerbangan domestik dan internasional. Bandara biasanya berlokasi pada daerah terpencil yang dapat diakses via akses langsung jalan tol atau jaringan transit daripada di tengah area metropolitan yang dibatasi oleh jaringan grid lokal, sehingga luas market mereka dapat diukur. Moda yang digunakan pada bandara Juanda didominasi kendaraan pribadi dan taksi. Pada kondisi seperti ini, pada jam puncak terjadi antrian pada areal penurunan dan naiknya penumpang beserta melebihi kapasitas pada area parkir. Informasi penggunaan moda sangat penting untuk diketahui. Metode yang digunakan adalah mengidentifikasi penggunaan kendaraan yang mengakses bandara, mengevaluasi kinerja lahan parkir, kinerja area pick up dan drop off, evaluasi jumlah antrian pada area pick up dan drop off, menghitung jumlah antrian jika disediakan transportasi massal untuk akses ke bandara. Hasil menunjukkan bahwa kendaraan pribasi mendominasi sebagai kendaraan yang mengakses bandara sebesar $87,78 \%$ dan kendaraan umum sebesar 12,23\%. Jam puncak kedatangan kendaraan pada pukul 9.00 am. Analisis pada penggunaan area drop off mengalami antrian sebesar 87,50\% dan kebutuhan lahan parkir sebesar 60,37\%. Pada Dasar usulan pengadaan transportasi massal mengurangi antrian pada area drop zone sebesar 12,42 \% dan kebutuhan parkir berkurang 39,62\%.
\end{abstract}

Kata Kunci: bandara, lahan parkir, area penurunan penumpang, transportasi massal 


\section{Pendahuluan}

Bandara Juanda Surabaya merupakan salah satu bandara dengan penumpang terbanyak di Indonesia. Pada sebuah pemikiran pakar ekonomi dan transportasi yang menyatakan bahwa dimana terjadinya peningkatan pendapatan yang dialami masyarakat sekitar dengan secara otomatis dapat mendorong trip maker dengan mobilitas yang tinggi dan sering (dapat jumlah perjalanan dan frekuensi perjalanan) [1]. Pertumbuhan penumpang pesawat yang terus bertambah sebelum pandemi dimulai, moda terdampak yang menuju dan dari Bandara Juanda seperti kendaraan pribadi dan angkutan umum. Pertumbuhan yang terus meningkat diluar pandemi yang menyebabkan penggunaan kendaraan pribadi pun meningkat linier dengan meningkatnya jumlah penumpang.

Pada suatu kasus tertentu akibat peningkatan jumlah kendaraan yang tidak seimbang serta fasilitas pelayanan pada bandara, dampaknya dapat dirasakan langsung pada pembebanan akses pada rut eke bandara tersebut.[2]. Bandara Juanda akan terganggu secara langsung aksesibilitasnya akibat pengaruh kinerja suatu pelayanan fasilitas bandara sisi darat terganggu. Mobilitas penumpang yang melalui jaringan jalan yang merupakan jalur untuk menuju bandara banyak melalui titik-titik ruas jalan yang kinerja ruas jalan dengan LOS D-F. Jika dilihat dari benbagai aspek, contohnya fasilitas sisi darat bandara yaitu fasilitas area naik dan turunnya penumpang (drop off and pick up) dan fasilitas pada area parkir adalah yang paling berdampak[3].

Yang dibutuhkan dalam perencanaan panjang drop off yaitu ditentukan oleh tipe dan volume lalu lintas yang diharapkan terjadi pada waktu puncak peak day[4]. Dalam tahun 2020 akhir bulan Agustus, perluasan terminal 1 sudah mencapai 96\% (juandaairport.com). Dimana dalam perluasan terminal 1 diharapkan dapat melayani kenaikan jumlah penumpang sampai 7 juta penumpang per tahun. Dikarenakan pandemik yang dialami pada awal tahun 2020 dengan berkurangnya jumlah penumpang sebesar $66,12 \%$ penumpang dari tahun 2019. Pada tahun 2020 jumlah penumpang sampai bulan oktober mencapai 5.633.188 penumpang domestik dan internasional pada bandara Juanda Surabaya. Sedangkan penumpang bandara Juanda pada tahun 2019 mencapai 16.626 .086 penumpang per tahun. Berikut merupakan gambaran layout pada terminal 1 bandara Juanda yang belum dilakukan peninjauan terhadap perluasan terminal.

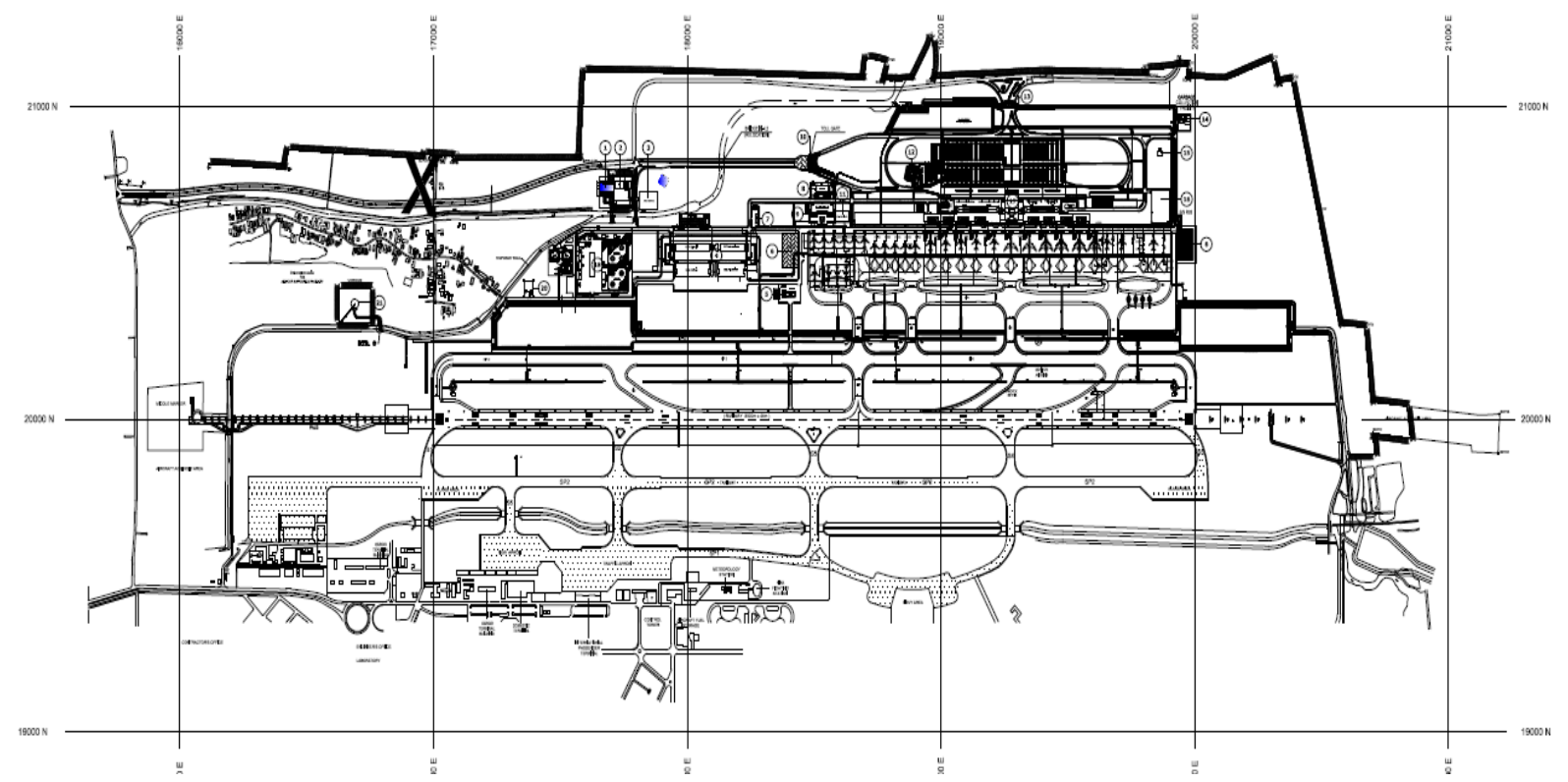

Gambar 1. Layout Terminal 1 Bandara Juanda

\section{Metode}

Pada penggambaran diagram alir pada tahapan analisis penggunaan moda dan karakteristik parkir bandara. Jika dalam analisis terpenuhi maka hanya meninjau kinerja parkir dan areal naik 
dan turunnya penumpang. Bila analisis karakteristik belum terpenuhi maka perlu adanya tinjauan kembali atas usulan pengadaan transportasi massal yang terjadwal karena transportasi massal yang sekarang seperti bus Damri dapat dikatakan kurang mendukung tersedianya transportasi massal dengan reliabilitas tinggi.

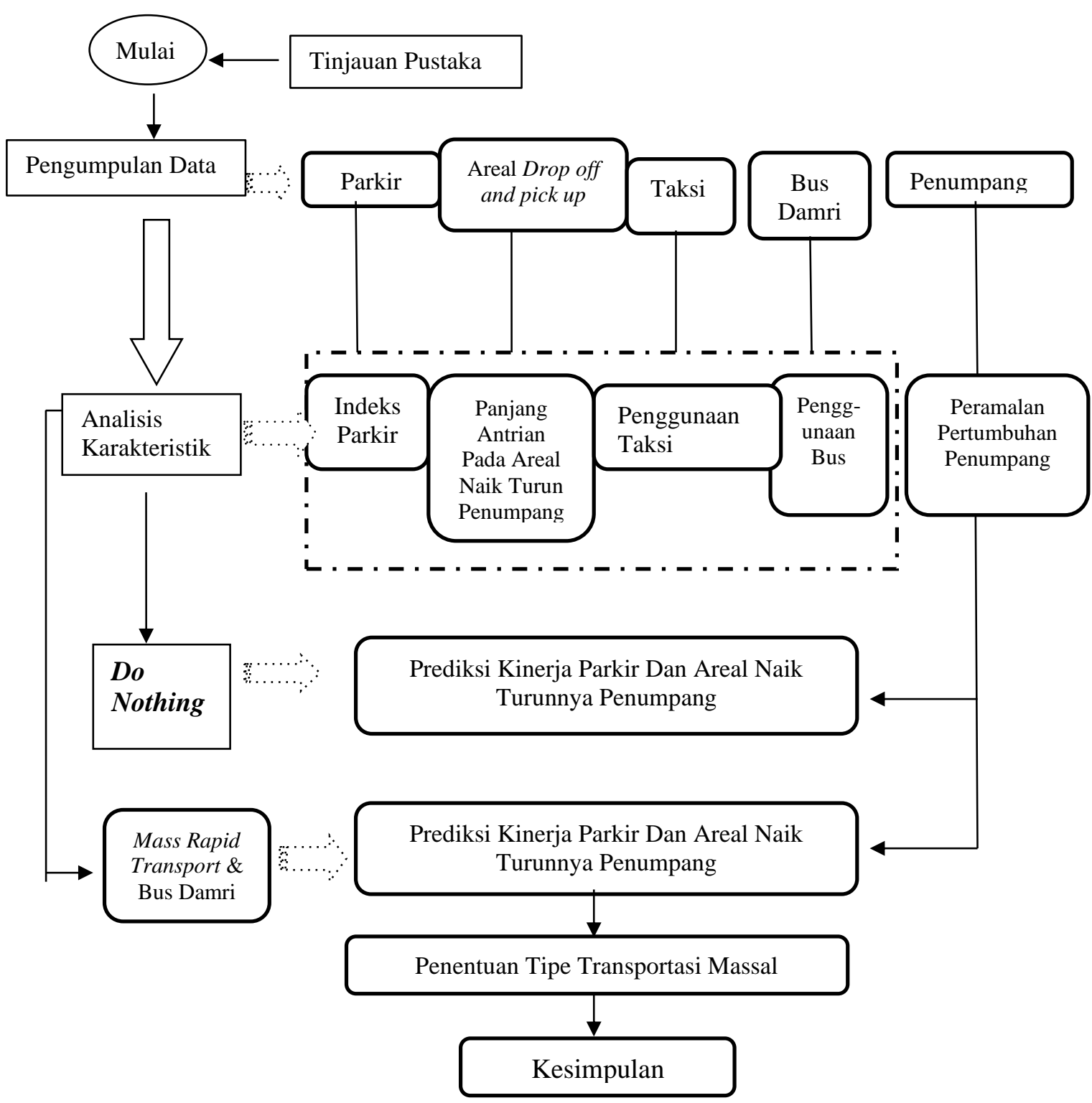

Gambar 2. Flowcart Analisis Penelitian

\section{Hasil dan Pembahasan}

Akibat kenaikan jumlah penumpang sebelum terjadinya pandemik yang menyebabkan salah satu kinerja layanan pada sisi land and air side terdampak. Selain hal tersebut yang paling penting merupakan pola distribusi kedatangan dan keberangkatan penumpang di bandara Juanda [5]. Hasil pembahasan dalam survey yang dilakukan dengan survey pencacahan jumlah kendaraan dan survey licence plate kendaraan. 
Tabel 1. Lokasi titik survey counting dan survey plat nomor

\begin{tabular}{|c|l|}
\hline $\begin{array}{c}\text { Titik } \\
\text { Survey }\end{array}$ & \multicolumn{1}{c|}{ Lokasi } \\
\hline 1 & Gate Masuk Bandara Juanda 1 (untuk roda 2) \\
\hline 2 & Gate Masuk Bandara Juanda 1 (untuk roda 4) \\
\hline 3 & Gate Parkir roda 2 \\
\hline 4 & Exit Gate Parking Lots (roda 2) \\
\hline 5 & Gate Tol Bandara (masuk) \\
\hline 6 & Gate Tol Bandara (keluar) \\
\hline 7 & Dropoff area \\
\hline 8 & Gate Bandara Juanda (Keluar untuk roda 2) \\
\hline 9 & Gate Bandara Juanda (keluar roda 4) \\
\hline
\end{tabular}

\section{(1) Data Jumlah Kedatangan Kendaraan}

Pengelompokkan kendaraan yang mengakses bandara yaitu : (1) Kendaraan Pribadi, (2) Taksi (online/ konvensional), dan (3) Bus Damri/ Bus Shuttle Bandara.

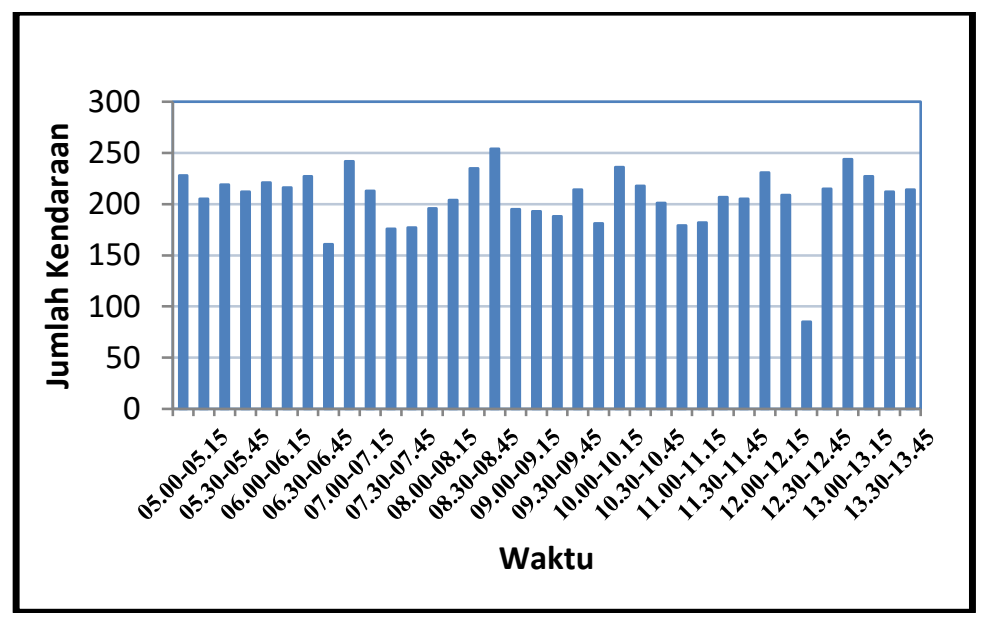

Gambar 3. Kendaraan masuk total pada Bandara Juanda

Banyaknya kendaraan (Kendaraan pribadi, taksi dan bus shuttle) yang mengakses bandara Juanda pukul 08.45-09.00 sebesar 343 kendaraan/ 15 menit. Pada pukul 12.30-12.45 sebesar 85 kendaraan. Darai gambar terlihat jika puncak terjadi di pukul 08.45-9.00.

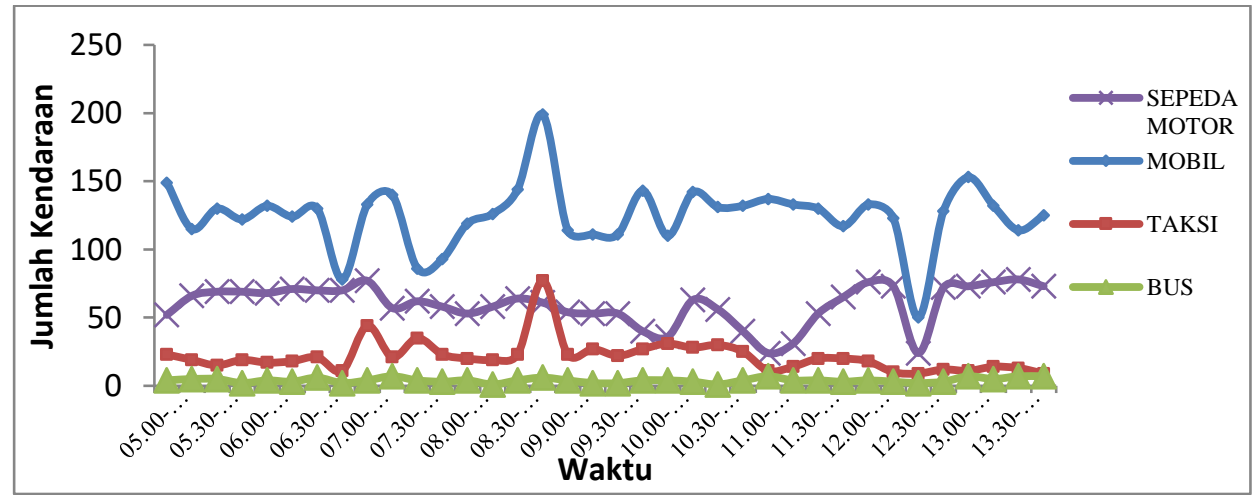

Gambar 4. Berdasarkan jenis kendaraan yang mengakses Bandara 
Kendaraan yang mengakses bandara masuk melalui 2 pintu masuk. Pintu masuk pertama melalui jalan konvensional, pintu masuk yang kedua yaitu menggunakan pintu masuk tol. Pintu masuk tol tidak dapat dilalui oleh kendaraan roda 2 , hanya kendaraan roda 4 saja yang dapat mengakses pintu tol.

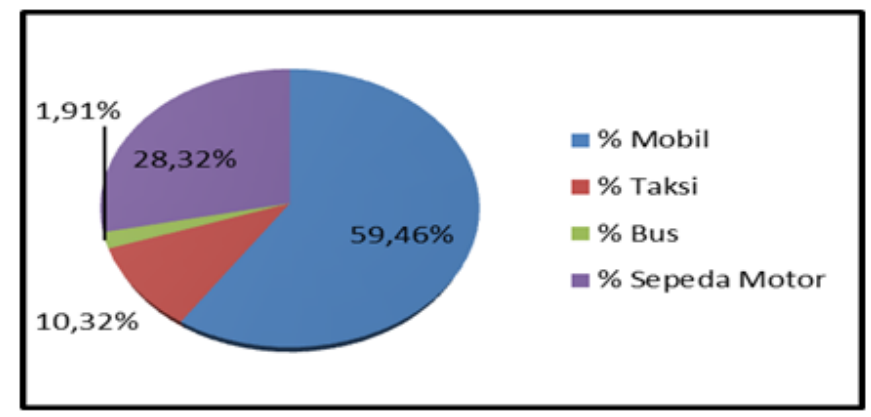

\section{Gambar 5. Jumlah Kendaraan Berdasarkan Jenis Kendaraan yang Mengakses Bandara Juanda}

Pada gambar 5 mayoritas moda yang digunakan adalah kendaraan pribadi sebesar $\pm 87,78 \%$, bus damri sebesar $1,91 \%$ dan taksi sebesar $10,32 \%$. Persentase penggunaan kendaraan pribadi lebih besar dari moda lain dalam kendaran yang mengakses bandara Juanda.

\section{(2) Karakteristik Kinerja Parking Lots}

Karakteristik kinerja parking lots tersebut antara lain volume parkir, akumulasi parkir, durasi parkir, kebutuhan lahan parkir, turn over parkir dan indeks parkir.

a. Volume Parkir

$V=E i+X$

Dimana: $\mathrm{X}=$ Jumlah kendaraan eksisting

$\mathrm{Ei}=$ Entry (jumlah kendaraan yang masuk)

Volume kendaraan sebesar 4531 kendaraan.

b. Akumulasi

Akumulasi parkir merupakan penjumlahan kendaraan yang terparkir pada parking lots ditambahkan dengan jumlah kendaraan yang mengakses masuk pada waktu tertentu. Rumus akumulasi adalah sebagai berikut:

Akumulasi $=E i-E x$

Dimana: $\mathrm{E}=\mathrm{J}$ Jumlah kendaraan yang mengakses parking lots

$\mathrm{E}_{\mathrm{x}}=$ Jumlah kendaraan yang keluar dari parking lots

Terdapat kendaraan eksisting pada saat survey, maka jumlah kendaraan eksisting dijumlahkan dalam akumulasi yang telah dihitung, perumusan dapat dituliskan sebagai berikut:

Akumulasi $=E i-E x+\mathrm{X}$

Dimana: $\mathrm{X}=$ Jumlah kendaraan eksisting

Akumulasi maksimum terjadi pada pukul 11 sebesar 1442 kendaraan.

Pada kendaraan yang masuk pada lahan parkir tertinggi sebesar 343 kendaraan. Dan terendah sebesar 85 kendaraan.

c. Durasi Parkir

Durasi parkir diperoleh dari waktu yang dibutuhkan kendaraan parkir per waktu tertentu, dengan perumusan adalah sebagai berikut:

Durasi parkir $=$ Waktu Ex - Waktu Ei

Dimana :

Waktu $\mathrm{E}$ = waktu kendaraan masuk ke parking lots

Waktu $\mathrm{E}_{\mathrm{x}}=$ waktu kendaraan keluar dari parking lots

Dari survei yang telah dilakukan diperoleh rata-rata durasi parkir 74 menit.

d. Kebutuhan Lahan Parkir 
Pada perhitungan kebutuhan parking lots merupakan SRP (satuan ruang parkir) yang dibutuhkan untuk kendaraan parkir pada parking lots. SRP yang tersedia 1520 SRP kendaraan roda 4. Tetapi eksisting SRP hanya 872 slots. Pada perhitungan akumulasi tertinggi sebesar 1442 kendaraan, dapat disimpulkan overcapacity terjadi di pukul 11.00-11.15 sebesar 570 kendaraan.

e. Turnover Parkir

Merupakan nilai yang menjadi indicator perbandingan antara waktu parkir dengan SRP yang tersedia (kapasitas statis) pada waktu tertentu [6]. Perumusan yang dipergunakan untuk mendapatkan nilai tersebut adalah

$$
\begin{aligned}
\text { Turnover parkir }= & \frac{\text { Volume parkir }}{\text { Kapasitas statis }} \\
& =4531 / 872=5,19
\end{aligned}
$$

Dari hasil tersebut, penelitian yang dilakukan selama 9 jam. Pada hasil SRP tersedia 872 petak parkir, setiap SRP mengalami pergantian kendaraan sebanyak 5x dalam waktu pengamatan 9 jam.

f. Indeks Parkir (IP)

Nilai indeks parkir merupakan indikator besaran kapasitas parkir yang terisi. Besaran IP didapatkan dari perbandingan antara akumulasi parkir dengan kapasitas SRP yang disediakan. Besaran IP menunjukkan Kawasan parkir tersebut tercukupi terhadap demand yang ada atau tidak. Hal tersebut dapat dirumuskan sebagai berikut.

$I P=\frac{A P}{\text { Petak Parkir Tersedia }}$

Dimana :

IP $<1$, yang menyatakan bahwa kebutuhan parkir tidak melebihi kapasitas normal.

IP $=1$, yang menyatakan bahwa kebutuhan parkir seimbang dengan kapasitas normal

IP > 1, yang menyatakan bahwa dimana kebutuhan parkir melebihi kapasitas normal

Sesuai perhitungan IP $=1442 / 872=1,653$

Jika IP > 1, yang menyatakan bahwa kebutuhan parkir melebihi kapasitas normal.

\section{(3)Analisis Antrian.}

Kinerja pada drop off area diperhitungkan dengan tujuan mengetahui jumlah antrian kendaraan masuk pada area drop off. Analisis antrian melalui 3 proses yaitu:

a. Data jumlah kendaraan pada peak day.

b. Data jumlah kendaraan pada saat survei dikorelasikan dengan jumlah penumpang pertahun.

c. Data jumlah kendaraan yang dikorelasikan dikurangi dengan asumsi kendaraan direncanakan $70 \%$ berpindah menggunakan transportasi masal.

Curbside digunakan untuk naik dan turunnya penumpang dari kendaraan dan merupakan jalur sirkulasi untuk kendaraan menuju dan meninggalkan terminal bandara [7]. Akses yang mudah menuju bandara adalah faktor penting yang mempengaruhi keberhasilan bandara secara keseluruhan [4]. Data yang dibutuhkan dalam menganalisis area dropoff menggunakan data yang diperoleh dari angkasa pura guna melihat data keberangkatan penumpang harian yang datanya akan dianalogikan sebagai data/ jumlah kendaraan yang mengakses bandara Juanda, data spesifikasi curbside (Panjang dan lebar), data lama waktu kendaraan mengakses curbside.

Spesifikasi Panjang pelayanan curbside sepanjang 75 m dengan kapasitas 12 kendaraan pada setiap jalurnya. Penggunaan di lapangan hanya 85\% dari panjang keseluruhan area curbside [4]. Sehingga untuk 10 kendaraan per lajurnya dengan occupancy 2 penumpang per kendaraannya [5]. Berikut analisis antrian melalui 3 proses:

a. Data jumlah kendaraan pada peak day.

Pada tabel 2 memperoleh arrival kendaraan pada peak day sebesar 1289 kendaran/waktu pengamatan. Skema nilai occupancy digunakan dengan asumsi per kendaraan dengan 2 orang penumpang per kendaraan. Asumsi kendaraan dating sebesar 644 kendaraan/jam, kemudian diubah ke satuan menit menjadi 11 kendaran/menit. Jumlah kendaraan kemudian dikalikan dengan waktu pelayanan 2,2 menit per kendaranan yang menggunakan curbside. Antrian dalam sistem sebesar 24 kendaraan per menit. Dari perhitungan kendaraan yang diluar antrian sistem sebesar 4 kendaraan/menit. 
Tabel 2. Perhitungan jumlah antrian pada saat peak day

\begin{tabular}{|c|c|c|c|c|}
\hline $\begin{array}{c}\text { Kedatangan } \\
\text { kendaraan } \\
\text { peak day } \\
\text { (kend/jam) } \\
(\mathbf{1})\end{array}$ & $\begin{array}{c}\text { Asumsi } \\
\text { kedatangan } \\
\text { kendaraan } \\
\text { (kend/jam) }\end{array}$ & $\begin{array}{c}\text { Asumsi } \\
\text { kedatangan } \\
\text { kendaraan } \\
\text { (kend/mnt) }\end{array}$ & $\begin{array}{c}\text { Jumlah } \\
\text { kendaraan } \\
\text { dalam sistem } \\
\text { (kend/mnt) } \\
(\mathbf{4})\end{array}$ & $\begin{array}{c}\text { Jumlah } \\
\text { antrian } \\
\text { kendaraan } \\
\text { (kend/mnt) }\end{array}$ \\
\hline 1289 & $\mathbf{( 2 )}$ & $\mathbf{( 3 )}$ & 24 & $\mathbf{( 5 )}$ \\
\hline
\end{tabular}

b. Data jumlah kendaraan pada saat survey dihubungkan dengan jumlah penumpang pertahun.

Pada tabel 3 pada kolom (1) arrival penumpang peak day sebesar 2125 penumpang. Pada hasil data arrival kemudian dibagi dengan occupancy sebesar 1062 kendaraan/jam. Jumlah kendaran antrian dalam sistem sebesar $39 \mathrm{kendaraan} /$ menit, dengan waktu pelayanan rata-rata selama ${ }_{-}+2,2$ menit, didapatkan antrian sebesar 19 kendaraan /menit pada area curbside.

Tabel 3. Asumsi perhitungan antrian berdasarkan total jumlah penumpang

\begin{tabular}{|c|c|c|c|c|}
\hline $\begin{array}{c}\text { Kedatangan penumpang } \\
\text { pada saat peak day } \\
\text { (pnp/jam) }\end{array}$ & $\begin{array}{c}\text { Asumsi kedatangan } \\
\text { kend. pada saat peak } \\
\text { day (kend/jam) } \\
\text { (2) }\end{array}$ & $\begin{array}{c}\text { Asumsi } \\
\text { kedatangan } \\
\text { kendaraan } \\
\text { (kend/menit) }\end{array}$ & $\begin{array}{c}\text { Jumlah kendaraan } \\
\text { dalam sistem } \\
\text { (kend/menit) }\end{array}$ & $\begin{array}{c}\text { Jumlah } \\
\text { antrian } \\
\text { kendaraan } \\
\text { (kend/menit) }\end{array}$ \\
\hline 2125 & 1062 & $\mathbf{( 3 )}$ & $\mathbf{( 4 )}$ & $\mathbf{( 5 )}$ \\
\hline
\end{tabular}

c. Data jumlah kendaraan yang dikorelasikan dikurangi dengan asumsi kendaraan direncanakan $70 \%$ berpindah menggunakan transportasi massal.

Pada data arrival kendaraan sebesar 930 kendaraan/jam, dengan asumsi kedatangan kendaraan yang telah dibag dengan occupancy yaitu 8 kendaraan/menit. Jumlah kendaraan yang sudah diketahui dalam perencanaan dikalikan dengan rata-rata waktu pelayanan yaitu 2,2 menit/kendaraan. Antrian dalam sistem yaitu 17 kendaraan/menit. Setiap 2 lajur akses curbside dapat menampung 20 kendaraan. Dapat disimpulkan 2 kendaraan sisa dan tidak terjadi antrian terhadap sistem antrian.

Tabel 4. Skema perhitungan antrian berdasarkan total kedatangan

\begin{tabular}{|c|c|c|c|c|}
\hline $\begin{array}{c}\text { Kedatangan } \\
\text { kendaraan } \\
\text { (kend/jam) }\end{array}$ & $\begin{array}{c}\text { Asumsi } \\
\text { kedatangan } \\
\text { kendaraan } \\
\text { (kend/jam) }\end{array}$ & $\begin{array}{c}\text { Asumsi } \\
\text { kedatangan } \\
\text { kendaraan } \\
\text { (kendaraan } \\
\text { /menit) }\end{array}$ & $\begin{array}{c}\text { Jumlah kendaraan } \\
\text { dalam sistem } \\
\text { (kendaraan/menit) } \\
\text { (4) }\end{array}$ & $\begin{array}{c}\text { antrian } \\
\text { kendaraan } \\
\text { (kendaraan } \\
\text { /menit) }\end{array}$ \\
\hline (1) & $(\mathbf{2})$ & $(3)$ & 17 & (5) \\
\hline 930 & 465 & 8 & & -2 \\
\hline
\end{tabular}

\section{(4) Rencana Pengadaan Transportasi Massal}

Moda yang digunakan dalam perencanaan ini merupakan kereta api. Kereta api dengan spesifikasi yang direncanakan adalah kereta api konvensional dengan kapasias temapt duduk sebanyak 385 seats. Skema asumsi kendaraan yang menggunakan tol $70 \%$ menggunakan transportasi massal. Dengan penumpang yang moving menggunakan transportasi masal adalah 716 penumpang peak hour. Berdasarkan hal tersebut membutuhkan 10 rangkaian dengan jumlah tempat duduk per rangkaian dengan spesifikasi 77 seats per rangkaian. Perencanaan kereta yang menuju dan dari bandara Juanda dengan headway 30 menit, dan ada 2 trip dalam satu jam kereta menuju bandara Juanda. 


\section{Kesimpulan}

1. Karakteristik kendaraan dari dan ke bandara Juanda sebagai berikut:

a. Peak Hour pukul 09.00. Dengan durasi rata-rata 1 jam 14 menit.

b. Persentase mobil pribadi dan motor yang menuju bandara sebesar $87,78 \%$.

c. Persentase angkutan umum yang mengakses bandara Juanda sebesar 12,3\% dengan pengguaan taksi (online dan konvensional) sebesar 10,32\% dan pengunaan bus Damri sebesar $1,91 \%$.

2. Analisis kabutuhan parking lots:

a. Parking lots yang digunakan konfigurasi $90^{\circ}$.

b. Jumlah kendaraan eksisting sebesar 4531 kendaraan.

c. Kapasitas parking lots sebesar 872 parkir

c. Nilai IP yang diperoleh sebesar 1,653.

3. Analisis Antrian

Perhitungan dengan menggunakan arrival jumlah kendaraan dan diakumulasikan pada total demand, sesuai hasil terdapat 19 kendaraan diluar antrian sistem curbside pada jalur 1. Antrian pada peak day sebesar 4 kendaraan per menit.

4. Transportasi masal kereta api bandara dengan kapasitas 385 tempat duduk, 5 rangkaian kereta. Perencanaan kereta dengan headway 30 menit dan kecepatan rata-rata 60 km/jam.

5. Perencanaan pengadaan transportasi massal dapat mengurangi antian curbside sebesar $\pm 12 \%$ antrian dan pengurangan pada demand lahan parkir sebesar $\pm 40 \%$.

\section{Referensi}

[1] O. Tamin, Perencanaan \& Pemodelan Transportasi, Penerbit ITB, ISBN 979-9299-10-1.

[2] J. Block, "Airport planning," Futures, vol. 1, no. 4, pp. 318-324, 1969, doi: 10.1016/00163287(69)90006-8.

[3] C. I. Hsu and Y. H. Wu, "The market size of a city-pair route at an airport," Ann. Reg. Sci., vol. 31, no. 4, pp. 391-409, 1997, doi: 10.1007/s001680050055.

[4] A. D. K. Subagustian, "Studi Tingkat Pelayanan (Level of Service) Curbside Keberangkatan Terminal 3 Ultimate Bandara Internasional Soekarno-Hatta," 2015.

[5] L. Fatchiyah and J. T. Sipil, "Terminal Penumpang Domestik Bandara Internasional Juanda ( Metode : Arima Dan Regresi Dummy ) on Different Forecasting Methods for Facility Planning of Domestic Passenger Terminal of Juanda Internasional Airport ( Method : Arima and Dummy Regression )," 2014.

[6] F. D. HOBBS, “Traffic Studies,” Traffic Plan. Eng., vol. V, pp. 42-93, 1979, doi: 10.1016/b9780-08-022697-2.50009-6.

[7] R. Horonjeff, F. McKelvey, W. Sproule, and S. Young, Planning and Design of Airports. 2010. 